\title{
JUURNAL_RU
}

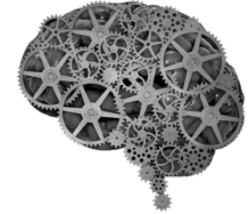

COMPANY GROUP "INTELLEKT"

\author{
Незнамов М.H. \\ Саратовский филиал Самарского медицинского университета «РЕАВИЗ» \\ Саратов, Россия
}

doi: 10.18411/1j2016-3-26

\section{Оценка ишемических нарушений в тканях методом активной радиометрии в СВЧ-диапазоне}

Оценка ишемического повреждения тканей у больных хирургического и травматологического профиля в настоящее время является актуальной научнопрактической задачей. Прогноз наступления ишемических повреждений приобретает особую значимость при временной остановке кровотечения. Однако, не смотря на внедрение в клинику визуальных методов диагностики, включая сонографические и изотопные технологии, в настоящее время, задача объективизации степени ишемии в полной мере не решена [1].

В этой связи активная радиометрия (АР), основанная на явлении преобразования водными средами низкоинтенсивных внешних электромагнитных излучений, являющаяся чувствительным методом оценки метаболической активности тканей, может быть рассмотрена в качестве перспективной технологии оценки степени тканевой ишемии [1].

Показана информативность AP в диагностике и мониторинге патологических изменений ткани легкого [2, 3], у пациентов с инфильтративновоспалительной патологией нижних отделов респираторного тракта [4-7], при оценке функционального состояния миокарда у пациентов с артериальной гипертонией $[8,9]$, при диагностике воспалительной патологии органов брюшной полости и травматологии [10-12]. Метод также позволяет оценивать 
функциональное состояние организма человека [13], а так же обеспечивать интегральную оценку воспалительной реакции $[14,15]$, проводить ее мониторинг и дифференцировать патологические состояния воспалительной и невоспалительной природы [16-18].

Цель исследования - оценка ишемических нарушений в условиях временной остановки кровотечения методом АР.

Материалы и методы исследования. Исследование проведено с участием 20 молодых добровольцев мужчин без сопутствующей патологии периферических артерий и вен возрасте 23-27 лет. Ишемия конечности создавалась наложением кровоостанавливающего жгута и модернизированного устройства временной остановки кровотечения (Маслов В.И., 1999 г.) на плечо на 15 минут. Состояние проницаемости капилляров для воды и белка исследовалось с помощью гидростатической пробы Казначеева В.П. и Дзизинского А.А, заключающейся в анализе гематокрита и уровня общего белка в венозном и артериальном сегменте кровеносной системы в условиях создания повышенного гидростатического давления в микроциркуляторном русле. Проба позволяет оценить степень сосудистой проницаемости в миллилитрах воды и граммах белка на 100 мл крови. Проба проводилась на 5 и 15 минуте ишемии.

В ходе исследования с помощью радиоэлектронного комплекса «Аквафон» и метода АР регистрировалась интенсивность излучения водосодержащих сред тканей плеча $[6,7]$. Оценка регистрируемого излучения производится в условных единицах: за 100 условных единиц принимается уровень излучения дистиллята воды при $37{ }^{0} \mathrm{C}$, что соответствует уровню мощности принимаемого излучения $\sim 10^{-14}$ Вт $[1,2,6]$.

Интенсивность излучения водосодержащих сред организма (волновая активность среды - ВА) регистрировалась с внутренней поверхности верхней трети предплечья исходно, на 5 и 15 минуте исследования. Исследование проводилось в утренние часы, натощак, в положении обследуемых сидя.

Результаты исследования. Полное прекращение кровотока в конечности 
сопровождалось резким усилением сосудистой проницаемости. Так, проницаемость сосудистой стенки для воды в первые 5 минут исследования возросла в 3 раза с 2,6 мл до 10,6 мл. В последующие 10 минут темп изменений несколько уменьшился, и к 15 минуте изменения ТКО достигли 4,5 кратного увеличения и составили -14,1 мл воды. Проницаемость сосудистой стенки для белка к 5 минуте возросла в 4,6 раза с 0,15 г до 0,82 г белка. К 15 минуте проницаемость для белка достигла 0,84 г.При наложении устройства временной остановки кровотечения в отличие от жгута, к 5-й минуте, отмечался менее выраженный рост сосудистой проницаемости (с 2,6 мл до 5,1 мл). Причем следует заметить, что к 15 минуте сосудистая проницаемость уменьшилась до 3,5 мл, приблизившись к верхней границе нормы. Уровень проницаемости для белка при наложении устройства оставался в пределах здоровых лиц. ВА при наложении жгута в первые 5 минут характеризовалась так же отрицательной динамикой, снижаясь со 110 до 75 ед., с последующим уменьшением к 15 минуте до 65 ед. При наложении устройства, в первые 5 минут нахождения жгута на плече, отмечалось снижение ВА со 110 до 89 ед., причем в последующем (к 15-й минуте исследования) регистрировалась отчетливо выраженная тенденция к восстановлению данного показателя, достигавшего к окончанию наблюдения 95 ед. - нижней границы нормы [2].

Таким образом, полное прекращение магистрального и коллатерального кровотока сопровождается усилением гидратации тканей и развитием тканевого отека, степень которого пропорциональна экспозиции ишемии. Волновая активность водосодержащих сред, тесно связанная с транскапиллярным обменом может быть использована для оценки степени перфузионных и метаболических нарушений $[6,8,9]$. 


\section{Литература:}

1. Избранные технологии диагностики: Монография / В.М. Еськов и др.; под ред. А.А. Хадарцева, В.Г. Зилова, Н.А. Фудина. Тула: ООО РИФ «ИНФРА», 2008. $296 \mathrm{c}$.

2. Терехов И.В. Транс-резонансная функциональная топография в диагностике заболеваний органов дыхания (новый метод обработки информации): автореф. дисс. канд. мед. наук, Тула, 2007. 24 с.

3. Применение метода ТРФ-топографии в диагностике воспалительных изменений нижних отделов респираторного тракта / Терехов И.В., Громов М.С., Парфенюк В.К. и др. // Саратовский научно-медицинский журнал. 2008. Т. 4. № 1. С. 79-83.

4. Возможность использования активной СВЧ-радиометрии для оценки альвеолярно-капиллярной проницаемости в эксперименте / Терехов И.В., Солодухин К.А., Аржников В.В. и др. // Регионарное кровообращение и микроциркуляция. 2011. Т. 10. № 4. С. 83-86.

5. Терехов И.В., Дзюба М.А., Наджарьян Л.С. Оценка альвеолярнокапиллярных нарушений при развитии тяжелого гемодинамического отека легких у крыс и их коррекция с помощью СВЧ-излучения // Саратовский научно-медицинский журнал. 2011. Т. 7. № 2. С. 389-392.

6. Терехов И.В. Оценка сосудистой проницаемости с помощью активной радиометрии // Аспирантский вестник Поволжья. 2009. № 7-8. С. 187-190.

7. Технология динамической оценки воспалительного процесса с помощью активной резонансной радиометрии / Терехов И.В., Громов М.С., Петросян В.И., Бондарь С.С. и др. // Вестник новых медицинских технологий. 2010. Т. 17. № 1. С. 135-137.

8. Использование радиоволнового зондирования водосодержащих сред миокарда у больных с артериальной гипертензией / Терехов И.В., Солодухин К.А., Никифоров В.С., Ломоносов А.В. // Российский кардиологический журнал. 2013. № 5 (103). С. 40-43.

9. Терехов И.В., Логаткина А.В., Бондарь С.С. Функциональное состояние миокарда и его связь с состоянием водосодержащих сред органов грудной клетки при инфильтративных процессах в легких // Stredoevropsky Vestnik pro Vedu a Vyzkum. 2015. T. 51. C. 3.

10. Применение транс-резонансной функциональной топографии с целью оптимизации диагностической тактики у пациентов с подозрением на острый панкреатит и его осложнения / Лобаков А.И., Громов М.С., 
Дубовицкий С.А., Тер-Симонян Г.В., Терехов И.В. и др. // Хирург. 2008. № 8. С. 22-33.

11. Трансрезонансная функциональная топография в оптимизации диагностики у пациентов с подозрением на острую воспалительную патологию органов брюшной полости / Громов М.С., Масляков В.В., Брызгунов А.В., Терехов И.В. и др. // Анналы хирургии. 2008. № 6. С. 60 63.

12. Идентификация и дифференциация костных новообразований методом активной радиометрии / Незнамов М.Н., Зайцев В.А., Ругина Н.А., Бондарь С.С., Терехов И.В. // Вестник новых медицинских технологий. Электронное издание. 2015. Т. 9. № 2. С. 20.

13. Громов М.С., Аржников В.В., Терехов И.В. Возможности оценки функционального состояния организма с помощью собственного радиоизлучения нетепловой природы // Медицинский вестник МВД. 2008. № 5 (36). С. 38-43.

14. Интегральная оценка воспалительного процесса у больных внебольничной пневмонией методом активной радиометрии / В.В. Аржников, В.Б. Лифшиц, В.К. Парфенюк, И.В. Терехов // Саратовский научно-медицинский журнал. 2011. Т. 7. № 4. С. 817-822.

15. Громов М.С., Терехов И.В. Характеристика системного воспалительного ответа у больных внебольничной пневмонией в динамике при помощи активной СВЧ-радиометрии // Казанский медицинский журнал. 2010. Т. 91. № 5. С. 611-614.

16. Терехов И.В., Парфенюк В.К. Мониторинг инфильтративных процессов нижних отделов респираторного тракта у пациентов с внебольничной пневмонией методом люминесцентного анализа в радиодиапазоне // Вестник восстановительной медицины. 2009. № 3. С. 46-50.

17. Диагностика и мониторинг инфильтративных процессов в грудной полости с помощью люминисцентного излучения водосодержащих сред / Аржников В.В., Терехов И.В., Громов М.С. // Медицинский вестник МВД. 2009. № 2 (39). С. 40-46.

18. Дифференциальная диагностика заболеваний грудной клетки с помощью транс-резонансной функциональной топографии / Терехов И.В., Петросян В.И., Громов М.С., Масляков В.В. и др. // Вестник медицинского института "РЕАВИЗ": реабилитация, врач и здоровье. 2013. № 3 (11). C. 18 - 